\title{
Cross-cultural adaptation and reliability of the pain response to activity and position questionnaire
}

\author{
Geisiane Rodrigues de Carvalho', Elenderjane Andrade de Oliveira', Vitor Tigre Martins Rocha², \\ Daniele Sirineu Pereira ${ }^{3}$ and Leani Souza Máximo Pereira ${ }^{2^{*}}$ (D)
}

\begin{abstract}
Background: The World Health Organization reports that one of the main incapacitating conditions in older adults is osteomusculoskeletal disorders, and among these is low back pain. There are few instruments translated and transculturally adapted with psychometric properties evaluated for older adults with this health condition in Brazil. The Pain Response to Activity and Positioning (PRAP) questionnaire enables classification of older adults through functional performance. The objective of this study was to perform a cross-cultural adaptation and verify the reliability of the PRAP for older Brazilian people with chronic low back pain.

Methods: A cross-sectional methodological study from the international study "Back Complaints in the Elders". We included individuals aged $\geq 60$ years, with chronic lumbar pain complaints lasting $\geq 3$ months. The transcultural translation and adaptation process followed the criteria proposed by Beaton and Guilhemeim, 1993. Reliability was tested using an unweighted Cohen's Kappa.

Results: Thirty-six (36) older adults participated in the study (71.15 \pm 7.23 years, $94.4 \%$ female). The intra-rater reliability for Low Back Pain (LBP) was between 0.50-1.00 and 0.23-0.84 for lower limbs, while the inter-rater reliability for LBP was between $0.25-0.63$ and between $0.18-0.53$ for lower limbs. The criteria for low back pain diagnosis showed intra and inter-rater agreement of 0.52 and 0.47 , respectively.
\end{abstract}

Conclusion: The Brazilian version of the instrument showed adequate reliability and ability to classify older adults in the diagnosis of LBP by reporting the performance of daily activities, and is indicated for use in the context of research and clinical practice.

Trial registration: There is no trial registration. This is a methodological study.

Keywords: Transcultural adaptation, Low back pain, Older adults

\section{Introduction}

With aging in Brazil being similar to the world population, the country is presenting a period of demographic and epidemiological transition [1], in which chronic musculoskeletal degenerative diseases are prevalent and incapacitating $[2,3]$. According to the World Health Organization (WHO), one of the main incapacitating conditions in the older population is musculoskeletal disorders, including

\footnotetext{
* Correspondence: leanismp.bh@terra.com.br

2Programa de Pós-Graduação em Ciências da Reabilitação, Departamento de Fisioterapia da Universidade Federal de Minas Gerais, Rua Groenlândia, 276/ 201-Sion CEP, Belo Horizonte, MG 30.320-060, Brazil

Full list of author information is available at the end of the article
}

low back pain (LBP) [3, 4]. Low back pain in older adults presents a less favorable prognosis $[5,6]$ and can progress to incapacities, falls, comorbidities and loss of autonomy, with high care costs for the public and private healthcare systems. A recent systematic review and meta-analysis showed that the prevalence of LBP at some time in life in older Brazilian adults was $25.0 \%(95 \% \mathrm{CI}=18.0-32.0)$ [7].

LBP can be classified according to its duration and can be defined as pain located below the last ribs and above the lower gluteal lines, presenting (or not) irradiation to the lower limbs [4]. Low back pain may be acute and have a sudden onset, lasting less than 6 weeks; subacute, lasting between 6 and 12 weeks; or chronic, lasting more

(c) The Author(s). 2019 Open Access This article is distributed under the terms of the Creative Commons Attribution 4.0 International License (http://creativecommons.org/licenses/by/4.0/), which permits unrestricted use, distribution, and 
than 12 weeks [8]. In addition, it may be of specific or non-specific origin. Unlike specific low back pain in which there is a cause and a certain pathological process, non-specific low back pain is characterized by the absence of structural alteration, i.e. there is no compression of nerve roots, bone or joint injury which can lead to pain in the spine; in this case, the justification for the cause of the pain symptoms occurs due to the mechanical imbalance between the functional load, which is the effort required for certain activities, and the capacity, which is the potential for execution [9].

Historically, research on "back pain" has been focused on the economically active young adult population, while little attention has been paid to the occurrence of this condition among the older adult population. There is a gap in the literature on low back pain in older adults, as most of the studies involving older adults are excluded due to cognitive changes or with the justification that they are not inserted in work activities. The anatomical bases for explaining LBP in older adults are different from those of young adults; osteoarthritis, osteoporosis, fractures, tumors, stenoses, associated comorbidities and polypharmacy are more prevalent in this age group. Moreover, outcomes such as falls, hospitalization and loss of functional independence are not reported in studies with young adults [10]. Pain in older adults can atypically manifest considering the physiological process of aging, associated comorbidities, polypharmacy, depression and others. LBP in older adults is difficult to diagnose and complementary imaging studies do not always reproduce the clinical picture. In a systematic review, Steffens et al. showed that the findings on MRI are not always associated with the diagnosis of low back pain [11]. LBP modifies and limits both physical and psychosocial aspects in the lives of older adults, often imposing changes which cause personal and family disorders, reduced functional capacity and interruption of life projects.

The proposal of cross-cultural adaptation and reliability of already existing questionnaires is being encouraged, as it normalizes/standardizes an international language. Due to the high financial cost and the difficulty in availability of complementary imaging exams by the public health system and that these do not always present the diagnosis for LBP symptoms, the present study aimed to perform a cross-cultural adaptation and verify the reliability of the Pain Response to Activity and Position (PRAP) questionnaire for older Brazilian adults with low back pain.

\section{Methodology}

This is a methodological study with a sub-sample of international multicentric research between Brazil, Australia and the Netherlands - Back Complaints in the Elders
(BACE), constituting a project approved by the Ethics and Research Committee of UFMG (ETIC.0100.0.203.000 11). The need for 30 older adults to evaluate the reliability of the instrument was verified from the sample calculation. Twelve (12) older adult patients with low back pain with a duration $>3$ months not attributed to infection, cancer or fracture were included, also having no history of spinal surgery and who signed the Free and Informed Consent Form (ICF). Older adults with cognitive deficits, identified by the Mental State Mini-Exam (MMSE) [12] were excluded from the study, as well as those with speech, auditory or visual impairments which impeded their performance on evaluations or those who presented exacerbated diseases.

\section{Instrument}

The Pain Response to Activity and Position Questionnaire (PRAP) is a self-reporting instrument by interview developed in the United States with the objective of categorizing individuals with LP as to the following possible diagnoses: benign lumbago (low back pain), spinal stenosis, intervertebral disc herniation and spinal stenosis associated with disc herniation, with performance guiding the treatment and informing the prognosis of this health condition [13]. The PRAP questionnaire consists of items selected to represent positions and activities that most people perform in their daily lives according to the biomechanical demands on the lumbar spine. The 15 items are divided into two sections of low back pain and lower limbs. In both sections individuals are asked to indicate which response best describes their pain when performing an activity: "No pain", "Better than before", "The same", "Worse" or "Not applicable". The presence of pain in the lower limbs also refers to intermittent claudication of neural origin felt during walking.

Subsections for each category are presented within the four classifications proposed by the instrument (spinal stenosis, disc herniation, disc herniation associated with stenosis and benign low back pain). In order for the individual to be classified into one of these categories, they must fill in at least one item of each subsection within the category under analysis until they complete all the prerequisites of the subsections and thereby establish one of the diagnostic classifications. The original English version of the questionnaire on the test-retest was moderate to high [14]. The results for low back pain were $0.46-0.89$ and $0.69-0.85$ for lower limbs, with questions about lower limbs presenting a better result than the general analysis.

\section{Procedures for cross-cultural translation and adaptation}

The translation and cross-cultural adaptation of the instrument was carried out according to the norms proposed by Beaton and Guilhemeim [15]. According to 
these authors, the cross-cultural adaptation process occurs in 6 steps. In the first step, two independent translations ( $\mathrm{T} 1$ and $\mathrm{T} 2$ ) were carried out by two Brazilian translators with English proficiency, with one of the translators not having knowledge of the domains of the questionnaire. In the second step, a synthesis of the two versions in Portuguese was elaborated, with the discrepancies between the translators being corrected and obtaining a single version (T1 T2). In the third step, a back-translation was performed from the synthesis of the two translations (T1 T2) by two independent and foreign bilingual translators who did not know the subject of the questionnaire. This step was aimed at verifying the correspondence of the Portuguese translation to the original content of the questionnaire. In the fourth and fifth steps, a committee of experts with methodological, linguistic and health knowledge discussed the semantic and cultural equivalence between the translated and the original versions, producing the pre-final version [15]. The pre-test was carried out in the sixth stage in which the pre-final version of the questionnaire was applied to the individuals included in the study. This procedure ensured that the adapted version still retained its equivalence in clinical practice.

\section{Procedures}

Two examiners were previously trained to ensure reproducibility and consistency in instrument application for the PRAP application. The older adults were invited to participate in the study through telephone calls, including those who met the inclusion criteria. The Mental State Mini-Exam was then applied [12] and those who were considered to have cognitive alterations were excluded. Sociodemographic and clinical data were concomitantly collected to the application of the PRAP questionnaire in order to characterize the sample.

\section{Statistical analysis}

After obtaining the final version of the instrument, an unweighted Cohen's kappa was used to examine the overall reliability and each item of the questionnaire. Kappa values less than zero were rated as "less than chance agreement", 0.01 to 0.20 "slight agreement", 0.21 to 0.40 "fair agreement", 0.41 to 0.60 "moderate agreement", 0.61 to 0.80 "substantial agreement" and 0.81 to 0.99 "almost perfect agreement" (Cohen J. 1968). The analyzes were performed in the Statistical Package for the Social Sciences (SPSS) version 23.0 program installed in Windows, with a significance level of $\alpha=5 \%$.

\section{Results}

Translation and transcultural adaptation

Some semantic "lean over and cultural adaptations were made to the questionnaire in the consensus phase of the specialists. In item 04, it was suggested to use the term the sink", and 09 "bend your body forward". In item 11, it was agreed that the interviewer could clarify to the interviewee that the expression "At the end of the day" refers to a typical day of your daily routine. In item 13, the expression "lawnmower" was replaced by the expression "furniture" as a result of cultural differences, since a lawnmower is not considered an instrument used by the majority of older adults. Another suggestion from the expert committee was regarding item 13 which contains the expression "something heavy", which was translated into Portuguese as "algo pesado", and items 14 and 15 which also address the issue of situations with "something heavy" were adapted to the daily reality, and the applicator can use examples of heavy objects that are present in the routine of the interviewee, such as: a rice package, a bucket with water or a heavy bag. There were no changes for the other items.

After the modifications, the questionnaire was considered coherent for the Brazilian culture, and is presented in Tables 1 and 2. The reapplication of the questionnaire with a minimum interval of 3 days and maximum of 10 days was advised by the authors of the original version and was followed in the present study.

\section{Sample characterization and reliability of the PRAP}

The sample of the present study consisted of 36 older adults interviewed in a 4-month period, aged between 60 and 90 years (mean $71.1 \pm 7.2$ ), predominantly female (94.4\%), and $47.2 \%$ were married. The sociodemographic and clinical characteristics of older adults are shown in Table 3.

There were 6 losses in relation to the second application phase of the questionnaire during the collection period, thus remaining with a total of 30 interviewees. The application time for each applicator varied from a minimum of $10 \mathrm{~min}$ and a maximum of $20 \mathrm{~min}$. After answering the questionnaire questions, the older adults were classified into four categories: spinal stenosis (28.08\%), disc herniation (10.67\%), disc herniation associated with stenosis and benign low back pain (19.66\%), benign low back pain (17.97\%), and no option (23.59\%).

For the intra-rater data, the results demonstrated reliability ranging from moderada to excellent for the spinal data $(0.50-1.00)$ and for the lower limb data $(0.23-0.84)$. The inter-rater reliability analysis demonstrated reliability ranging from fair agreement to substantial agreement for spinal data $(0.25-0.63)$, and values ranging from slight agreement to moderate agreement for lower limb data $(0.18-0.53)$. It was not possible to obtain the data analysis for some of the items of the questionnaire when investigating the reliability for individual items, demonstrating a disagreement among respondents' answers. These results may be related to variability in reliability in the lower back and lower limb sections. Moderate intrarater agreement and moderate inter-rater agreement of 
Table 1 Final version of the Pain Response to Activity and Position Questionnaire (PRAP)

\begin{tabular}{|c|c|c|c|c|c|}
\hline Positions and activities & No pain & Better & The same & Worse & N/A \\
\hline 1 When you stand for more than 5 min. & () & () & () & () & () \\
\hline 2 When you walk a block or more. & () & () & () & () & () \\
\hline 3 When you sit for more than 5 min. & () & () & () & () & () \\
\hline 4 When you lean over the sink. & () & () & () & () & () \\
\hline 5 When you drive a car. & () & () & () & () & () \\
\hline 6 When you lie on your back. & () & () & () & () & () \\
\hline 7 When you lie on your side. & () & () & () & () & () \\
\hline 8 When you lie on your stomach. & () & () & () & () & () \\
\hline 9 When you cough or bend your body forward. & () & () & () & () & () \\
\hline 10 When you wake up in the morning. & () & () & () & () & () \\
\hline 11 At the end of the day. & () & () & () & () & () \\
\hline 12 When you move from the sitting position to the standing position. & () & () & () & () & () \\
\hline 13 When you push something heavy like a vacuum cleaner or furniture. & () & () & () & () & () \\
\hline 14 When you lift heavy objects off the floor. & () & () & () & () & () \\
\hline 15 When you carry heavy objects. & () & () & () & () & () \\
\hline
\end{tabular}

0.52 and 0.47 were found $(p<0.05)$ in analyzing the use of classification criteria for diagnosis of low back pain by PRAP (Landis \& Koch, 1977).

\section{Discussion}

The present study of translating and adapting the Pain Response to Activity and Position Questionnaire demonstrated adequate reliability of the instrument for classifying older adults in relation to diagnosing low back pain from performing daily activities. According to Lima Costa et al., LBP is one of the most reported symptoms by older Brazilian adults. However, its diagnosis is complex and its treatment is not always effective. The World Health Organization (WHO) bulletin on LBP also highlighted the importance of this public health problem for different cultures and highlighted the frequent misunderstandings in the approach to this morbidity [16] due to the high costs, difficult availability of complementary exams by the public health system and also an inconsistency between the findings of imaging tests and the symptomatology of low back pain in older adults. Thus, the availability of standardized and reliable instruments which aid in diagnosing, identifying and approaching symptoms can contribute to an effective therapeutic approach of this health condition [17].

Each step in the cross-cultural adaptation process of the instrument was carried out in a judicious way, following methodological frameworks described in the literature [15] in order to obtain the conceptual, semantic and operational equivalence of the questionnaire, as well as considering the necessary adaptations. The PRAP questionnaire has generally proven to be an instrument of good understanding and easy application for older adults, and does not require much time for its application. No difficulty was detected on the part of the participants regarding understanding the issues considering the need to exemplify some aspects and terms related to routine activities in Brazilian culture. The use of the questionnaire in clinical practice becomes viable when relating pain symptoms to activities and movements/actions performed in the daily activities and tasks of older adults. These results are corroborated in the study in which the instrument was tested/applied in a population with low back pain through tests which integrate the international multicenter study [18].

Patients with low back pain commonly complain of changes in functionality, with negative repercussions in day-to-day tasks $[19,20]$. When directing its evaluation to the performance of daily activities, the PRAP considers partial or total disabilities due to low back pain and its course, allowing the health professional to establish a relationship between symptoms and targeting the therapeutic intervention.

According to the International Association for the Study of Pain (IASP), pain is defined as an unpleasant sensory and emotional experience described in terms of actual or potential tissue damage. It is always subjective, and each individual learns to use this term through their previous and traumatic experiences [21]. Parallel to such complexity, the aging process produces anatomical and functional modifications in the nociceptors, changes in conduction and in the perception of painful stimuli. Also, factors such as atypical manifestations of diseases, comorbidities, affectivity, resilience, and the use of medications are also aspects which may interfere in the manifestation of pain symptoms in more advanced age groups [22]. 
Table 2 Diagnostic classification criteria through PRAP

\begin{tabular}{|c|c|}
\hline Classification criteria for spinal stenosis & Classification criteria for benign low back pain \\
\hline $\begin{array}{l}\text { If at least one of these five symptoms is present: } \\
\text { 1. Back pain is worse when you stand } \\
\text { 2. for more than } 5 \text { min. } \\
\text { 3. Back pain is worse when walking for a block or more. } \\
\text { 4. Leg pain is worse when carrying heavy objects. } \\
\text { 5. Leg pain is worse when you push heavy objects. } \\
\text { 6. Leg pain is worse when standing for more than } 5 \text { min. }\end{array}$ & $\begin{array}{l}\text { If at least one of these two symptoms is present: } \\
\text { 1. Back pain is worse when sitting for more than } 5 \text { min. } \\
\text { 2. Back pain is worse when walking for more than one block. }\end{array}$ \\
\hline $\begin{array}{l}\text { And at least one of these two symptoms is present: } \\
1 \text { Back pain is absent, better, or does not change when sitting } \\
\text { for more than } 5 \text { min. } \\
2 \text { Leg pain is absent, better, or does not change when sitting } \\
\text { for more than } 5 \text { min. }\end{array}$ & $\begin{array}{l}\text { And at least one of these three symptoms is present: } \\
\text { 1. Back pain is absent, better, or does not change when moving from } \\
\text { sitting to standing. } \\
\text { 2. Leg pain is absent, better, or does not change when moving from } \\
\text { sitting to standing. } \\
\text { 3. Leg pain is absent, better, or does not change when walking for more } \\
\text { than one block. }\end{array}$ \\
\hline $\begin{array}{l}\text { And at least one of these two symptoms is present: } \\
1 \text { Leg pain is absent, better, or does not change when waking } \\
\text { up in the morning. } \\
2 \text { Leg pain is absent, better, or does not change at the end of } \\
\text { the day. }\end{array}$ & $\begin{array}{l}\text { And at least one of these three symptoms is present: } \\
\text { 1. Leg pain is absent, better, or does not change when sitting for more } \\
\text { than five minutes. } \\
\text { 2. Leg pain is absent, better, or does not change when lifting heavy } \\
\text { objects. } \\
\text { 3. Leg pain is absent, better, or does not change when leaning forward. }\end{array}$ \\
\hline \multirow[t]{3}{*}{ Classification criteria for disc herniation } & Classification criteria for disc herniation with spinal stenosis \\
\hline & $\begin{array}{l}\text { If at least one of these three symptoms is present: } \\
1 \text { Back pain is worse when pushing heavy objects. } \\
2 \text { Leg pain is worse when carrying heavy objects. } \\
3 \text { Leg pain is worse when standing for more than five minutes. }\end{array}$ \\
\hline & $\begin{array}{l}\text { And at least one of these two symptoms is present: } \\
1 \text { Back pain is worse when waking up in the morning. } \\
2 \text { Leg pain is worse when driving a car. }\end{array}$ \\
\hline \multicolumn{2}{|l|}{$\begin{array}{l}\text { If at least one of these four symptoms is present: } \\
1 \text { Back pain is worse when driving a car. } \\
2 \text { Back pain is worse when sitting for more than } 5 \text { min. } \\
3 \text { Leg pain is worse when driving a car. } \\
4 \text { Leg pain is worse when sitting for more than } 5 \text { min. }\end{array}$} \\
\hline $\begin{array}{l}\text { And at least one of these three symptoms is present: } \\
\text { 1. Leg pain is absent, better, or does not change when pushing } \\
\text { heavy objects. } \\
\text { 2. Leg pain is absent, better, or does not change when standing } \\
\text { for more than } 5 \text { min. } \\
\text { 3. Leg pain is absent, better, or does not change when lying on } \\
\text { stomach. }\end{array}$ & \\
\hline
\end{tabular}

Although the reliability of the PRAP was identified as adequate, variability with no agreement was observed in some items of the questionnaire. It is important to consider the complexity, multidimensionality and multiple factors involved in the pain event in the reliability analysis of instruments which involve pain charts, especially in older adults. In this context, the sample of the present study presented some health conditions which may have contributed to such results, among them osteoarthritis and the presence of depressive symptoms. Osteoarthritis presents a clinical picture of mechanically characteristic pain and symptoms which may oscillate over time according to the physical effort performed by the individual [23]. Pain may occur with less intense activities as the disease progresses $[24,25]$. The presence of depressive symptoms associated with low back pain is a warning sign because of its impact on physical function, independence and quality of life. Both health conditions identified in the sample may have influenced the results in the reliability analysis. Despite this influence, we chose to not exclude these health conditions in the present study in order to guarantee their external validity, since they are common in both the low back pain population and in the older adult population. Osteoarthritis and spondylosis were among the comorbidities of the osteoarticular system reported by the older adult participants, constituting degenerative articular diseases which are common with aging and included in the diagnostic classification criteria after applying the questionnaire [23].

Although it was not the objective of the study to investigate the construct validity of the instrument from the comparison of PRAP results with imaging tests, such an evaluation was conducted by Roach et al. when applied 
Table 3 Description of Participants

\begin{tabular}{|c|c|c|}
\hline Variables & $\mathrm{n}$ & $\%$ \\
\hline Age (mean in years) & $71.14(7.22)$ & 71.15 \\
\hline \multicolumn{3}{|l|}{ Gender } \\
\hline Female & 34 & 94.4 \\
\hline Male & 02 & 05.6 \\
\hline \multicolumn{3}{|l|}{ Civil status } \\
\hline Married & 17 & 47.2 \\
\hline Single & 06 & 16.7 \\
\hline Widowed & 11 & 30.6 \\
\hline Divorced & 02 & 05.5 \\
\hline \multicolumn{3}{|l|}{ Education } \\
\hline Illiterate & 04 & 11.1 \\
\hline Incomplete elementary & 12 & 33.3 \\
\hline Completed elementary & 07 & 19.4 \\
\hline Completed highschool & 08 & 22.2 \\
\hline Completed university/college & 05 & 13.9 \\
\hline \multicolumn{3}{|l|}{ Occupation } \\
\hline Retired & 32 & 88.9 \\
\hline Pensioner & 01 & 02.8 \\
\hline Homemaker & 02 & 05.6 \\
\hline \multicolumn{3}{|l|}{ Comorbidities } \\
\hline $\mathrm{SAH}$ & 23 & 63.9 \\
\hline Diabetes & 16 & 44.4 \\
\hline Arthrosis & 03 & 8.3 \\
\hline Spondylosis & 01 & 2.8 \\
\hline Depression & 08 & 22.2 \\
\hline Fibromyalgia & 02 & 05.6 \\
\hline \multicolumn{3}{|l|}{ Health perception } \\
\hline Excellent & 01 & 02.8 \\
\hline Very good & 02 & 05.6 \\
\hline Good & 15 & 41.7 \\
\hline Reasonable & 12 & 33.3 \\
\hline Bad & 06 & 16.7 \\
\hline
\end{tabular}

to 106 patients with low back pain recruited from tertiary services. These authors reported that the criteria proposed for PRAP diagnosis were broadly compatible with the clinical expectations for these diagnoses. The algorithm for disc herniation was consistent with the typical clinical picture of disc herniation, where flexion activities exacerbate pain and relief activities relieve pain. Likewise, the algorithm for spinal stenosis was consistent with the clinical literature, which describes patients experiencing pain relief with flexion and exacerbation of pain with extension [26]. The screening algorithm for spinal stenosis disc herniation included flexion and extension activities which increased LP or pain in the legs in patients with disc herniation or with spinal stenosis, respectively [26].

The study has some limitations the sample size was small and the instrument is not valid to monitor the response to therapeutics because the "sensitivity to change" was not tested. Even with the presented limitations, the questionnaire presented adequate reliability, demonstrating its ability to evaluate and classify low back pain as to its diagnosis based on the performance of functional activities.

\section{Conclusion}

The Pain Response to Activity and Position Questionnaire (PRAP) proved to be an instrument with acceptable reliability, semantically comprehensible for the older Brazilian population and presented good reproducibility by the applicators and possibilities for a diagnosis without complementary exams. The evaluation of low back pain associated with the performance of daily functional activities enables professionals to identify daily situations that the patient could/should avoid by contributing the most effective results of the therapeutic proposals.

\section{Acknowledgements}

We do not have thanks.

Published study protocol

MC Musculoskelet Disord. 2011 Aug 19;12:193. doi: https://doi.org/10.1186/ 1471-2474-12-193.Back complaints in the elders (BACE); design of cohort studies in primary care: an international consortium. Scheele J, Luijsterburg PA, Ferreira ML, Maher CG, Pereira LSM, Peul WC, van Tulder MW, Bohnen AM, Berger MY, Bierma-Zeinstra SM, Koes BW.

\section{Authors' contributions}

GRdeC and EAdeO: Participated in the study data collection, discussion and the article writing. VTMR e DSP: Participated in the statistical analysis, data discussion and the article writing. LSMP: Participated in the elaboration of the research, data collection, statistical analysis, data discussion and the article writing. All authors read and approved the final manuscript.

Funding

This research did not have financing.

Availability of data and materials

Materials and data available for consultation.

Ethics approval and consent to participate

Project approved by the Ethics and Research Committee of UFMG(ETIC.0100.0.203.000-11).

All participants signed a consent agreeing to participate in the study, according to the principles' Declaration of Helsinki (1969).

\section{Competing interests}

The authors declare that they have no competing interests.

\section{Author details}

${ }^{1}$ Departamento de Fisioterapia, Universidade Federal de Minas Gerais, Belo Horizonte, Brazil. ²Programa de Pós-Graduação em Ciências da Reabilitação, Departamento de Fisioterapia da Universidade Federal de Minas Gerais, Rua Groenlândia, 276/ 201-Sion CEP, Belo Horizonte, MG 30.320-060, Brazil.

${ }^{3}$ Departamento de Fisioterapia da Universidade Federal de Minas Gerais, Belo Horizonte, Brazil. 
Received: 9 July 2019 Accepted: 15 November 2019

Published online: 02 December 2019

\section{References}

1. Kilsztajn S, Rossbach A, Câmara MB, Carmo MSN. Serviços de saúde, gastos e envelhecimento da população brasileira. Revista Brasileira de Estudos de População. 2013;20(1):93-108

2. Murray CJL, Phil D, Lopez AD. Measuring the global burden of disease. $N$ Engl J Med. 2013;369(5):448-57.

3. World Health organization (2002). Active ageing: a policy framework. [publicação online]; 2002 [acesso em 30 abr 2019]. Disponível em WHOActive-Ageing-Framework.pdf.html.

4. Van Middelkoop M, Rubinstein SM, Verhagen AP, Ostelo RW, Koes BW, van Tulder MW. Exercise therapy for chronic nonspecific low-back pain. Best Pract Res Clin Rheumatol. 2010;24(2):193-204.

5. Ghanei I, Rosengren BE, Hasserius R, Nilsson JA, Mellstrom D, Ohlsson C, et al. The prevalence and severity of low back painand associated symptoms in 3,009 old men. EurSpine J. 2014;23(4):814-20.

6. Hoy D, Bain C, Williams G, March L, Brooks P, Blyth F, et al. Asystematic review of the global prevalence of low back pain. Arthritis Rheum. 2012; 64(6):2028-37

7. LeopoldinoAAO DJBM, Martins VT, Henschke N, LSM P, Dias RC, et al. Prevalence of low back pain in older Brazilians: a systematic review with meta-analysis. Rev Brasileira de Reumatologia. 2016;56(3):258-69.

8. Bratton RL. Assessment and management of acute low back pain. Am Family Physician. 1999:60(8):2299-306

9. Lizier DT, Perez MV, Sakata RK. Exercícios para Tratamento de Lombalgia Inespecífica. Rev Bras Anestesiol. 2016;62(6):838-46.

10. Wong AY, Karppinen J, Samartzis D. Low back pain in older adults: risk factors, management options and future directions. Scoliosis Spinal Disord. 2017;12:14.

11. Steffens D, Hancock MJ, Maher CG, Williams C, Jensen TS, Latimer J. Does magnetic resonance imaging predict future low back pain? A systematic review. Eur J Pain. 2014;18(6):755-65.

12. Bertolucci PHF, SMD B, Campachi SR, Juliano Y. O Mini-Exame do Estado Mental em uma população geral: impacto da escolaridade. Arq NeuroPsiquiatria. 1994;52(1):1-7.

13. Roach KE, Brown MD, Albin RD, Delungr KG, Lipprandt HM, Rangelli $D$. The sensitivity and specificity of pain. Response to activity and position in categorizing patients with low Back pain. Phys Ther. 1997; 77(7):730-8.

14. Roach KE, Brown MD, Dunigan KM, KusekCL, Walas M. Test-Retest reliability of patient reports of Back pain. JOSPT. 1997;26(5):253-9.

15. Guillermin F, Beaton C, Bombardier D. Cross-cultural adaptation of healthrelated quality of life measures: literature review and proposed guidelines. J Clin Epidemiol. 1993;46(12):1417-32

16. Ehrlich GE. Low Back pain. Bull World Health Organ. 2003;81(9):671-6.

17. Lima-costa MF, Barreto SM, Guiatti L. Condições de saúde, capacidade funcional, uso de serviços de saúde e gastos com medicamentos da população idosa brasileira: um estudo descritivo baseado na Pesquisa Nacional por Amostra de Domicílios. Cad Saude Publica. 2003;19(3):735-43.

18. Scheele J, Luijsterburg PA, Ferreira ML, Maher CG, Pereira L, Peul WC, et al. Back Complaints in the Elders (BACE); design of cohort studies in primary care: an international consortium. BMC Musculoskelet Disord. 2011:12:193.

19. Waddell G. The Back pain revolution. 2nd ed. New York: Churchill Livingstone; 2004.

20. Scheele J, Enthoven WTM, Bierma-Zeinstra SMA, Peul WC, Tulder MW, Bohnen AM, et al. Characteristics of older patients with back pain in general practice: BACE cohort study. Eur J Pain. 2013;18(2):279-87.

21. Teixeira MJ, Raia AA, Zerbini EJ. Tratamento neurocirúrgico da dor. 4th ed. São Paulo: Sarvier; 1988.

22. Lima MAG, Trad LAB. A dor crônica sob o olhar médico: modelo biomédico e prática clínica. Caderno Saúde Pública. 2007;23(11):2672-80.

23. Dionne CE, Dunn KM, Croft PR. Does back pain prevalence really decrease with increasing age? A sistematicreview. Age Ageing. 2006; 35(3):229-34.

24. Rezende MU, Campos GC, Pailo AF. Conceitos atuais em osteoartrite. Acta Ortopédica Brasileira. 2013;21(2):120-2.

25. Wolfe F, Smythe HA, Yunus MB, Bennett RM, Bombardier C, Goldenberg DL, et al. The American College of Rheumatology 1990 Criteria for the
Classification of Fibromyalgia. Report of the Multicenter Criteria Committee. Arthritis Rheum. 1990:33(2):160-72.

26. Magee DJ. Avaliação musculoesquelética. 5th ed. São Paulo: Manole; 2010.

\section{Publisher's Note}

Springer Nature remains neutral with regard to jurisdictional claims in published maps and institutional affiliations.
Ready to submit your research? Choose BMC and benefit from:

- fast, convenient online submission

- thorough peer review by experienced researchers in your field

- rapid publication on acceptance

- support for research data, including large and complex data types

- gold Open Access which fosters wider collaboration and increased citations

- maximum visibility for your research: over $100 \mathrm{M}$ website views per year

At BMC, research is always in progress.

Learn more biomedcentral.com/submissions 